\title{
Oscillating Frequency Approach for Void Fraction Measurements in Two-Phase Flow
}

\author{
Ahmed Elsaftawy, John Potts, James Chapman-Brown, Wael Ahmed \\ School of Engineering, University of Guelph \\ 50 Stone Road East, Guelph, Canada \\ elsaftaa@uoguelph.ca; potts@mail.uoguelph.ca; jchapm04@uoguelph.ca; ahmedw@uoguelph.ca
}

\begin{abstract}
In this paper, a high resolution capacitance sensor system was developed for two-phase flow void fraction measurements and flow pattern identification. The circuit uses the LC approach whose oscillation frequency changes as the capacitance sensor value fluctuates. This change in frequency is measured and converted in to a capacitance value. The electrodes' excitation frequency is high enough to overcome the errors involved when conductive fluids are used. A LabView program was designed to interface the circuit and to record the data collected. The capacitance sensor was built with four concave electrodes and was shielded with a copper cage. The system was tested on a vertical air-water two phase flow pipe with 1.5 inch outer diameter and 1.25 inch inner diameter.
\end{abstract}

Keywords: Two-Phase, Void Fraction, Capacitance Sensor, Flow Pattern Identification.

\section{Introduction}

Two-phase flow is the simultaneous flow of a mixture in two different phases such as gas-liquid, liquid-solid and gassolid. The most common type is the liquid-gas two-phase flow which is found many applications and industries such as oilgas transportation systems, heat exchangers and sewage treatment plants. Two-phase flows are characterized by their flow patterns (also known as flow regimes) which describe the phase arrangement or distribution along the flow. The main flow patterns in vertical pipes are plug, slug, bubbly, churn and annular flows, while the main flow patterns in horizontal pipes are bubbly, plug, stratified, wavy, slug, and annular flows [1,2].

Another important parameter used to characterize two-phase flows is the cross-sectional void fraction $(\alpha)$ which represents the fraction of the flow channel's cross-sectional area that is occupied by the gas phase. The cross-sectional void fraction is defined in Eq. (1) where $\mathrm{A}_{\mathrm{G}}$ and $\mathrm{A}_{\mathrm{L}}$ are the cross-sectional areas occupied by gas and liquid, respectively [3].

$$
\alpha_{\text {cross-sectional }}=\frac{A_{G}}{A_{G}+A_{L}}
$$

Void fraction measurements are essential when modelling two-phase flow systems. Therefore, several methods have been developed to measure void fraction such as quick closing valves [4], gamma-ray absorption [5,6], capacitance sensors and conductance sensors $[7,8]$. However, capacitance sensors are the most attractive option for most applications since they are non-intrusive and easy to manufacture.

Capacitance sensors are composed of one or more pairs of electrodes placed opposite to one another on the outer surface of the dielectric pipe walls. The electrodes are connected to an interface circuit which measure the capacitance of the flow channel between the electrodes at a high sampling rate. As the void fraction in the channel changes, the capacitance also changes. The principle behind this is that the dielectric constant of the liquid phase is different from the dielectric constant of the gas phase. The relation between dielectric constant and capacitance $\mathrm{C}$ is given in Eq. (2), where $\varepsilon_{\mathrm{r}}$ is the total dielectric constant of the working fluids and the pipe walls enclosed by the electrodes, $\varepsilon_{0}$ is the dielectric constant of free space which is $8.854 * 10^{-12}$, A is the surface area of the electrodes and $\mathrm{d}$ is the average distance between the electrodes. 


$$
\mathrm{C}=\frac{\varepsilon_{0} \varepsilon_{r} A}{d}
$$

Capacitance electrode configurations previously investigated by other researchers are the ring, concave and helical type. Helical electrodes were found to have low sensitivity, non-linear response and poor shielding [11]. On the other hand, ring and concave type electrodes have linear relationship between void fraction and capacitance value [10]. It was also found that concave electrodes have higher sensitivity than both the ring and helical [11-12]. There are several capacitance measuring techniques which can be used to measure the capacitance sensor. The common ones are the charge-balancing, AC bridge and the LC approach. An extensive review of each approach was done by [13].

In this paper, a capacitance sensor system was developed for two-phase flow void fraction measurements and flow pattern identification. The circuit is based on the LC approach which has the advantage of being noise immune due to the narrow band characteristics of the parallel LC circuit. As was suggested by other researchers, a high electrode excitation frequency was used to avoid some of the errors encountered when working with conductive fluids.

\section{Experimental Methodology}

The two-phase flow loop used for testing the developed system is shown in fig. (1). The system is composed of three main parts: the capacitance sensor, the interface circuit and the LabView program. A block diagram of the system is shown in fig. (2). The sensor consists of two pairs of copper electrodes placed on the outer surface of a vertically mounted polycarbonate pipe with 1.5 inch outer diameter and 1.25 inch inner diameter. To shield the sensor, the electrodes were enclosed in copper shielding which acts as a Faraday's cage to minimizing the external EMI interference. Two semicylindrical acrylic blocks with 0.75 " wall thickness were manufactured to separate the copper cage from the electrodes. The sensor electrodes were connected to the interface circuit (FloNergia Inc.()) using a shielded coaxial cable. Both the copper cage and the coaxial cable shielding where connected to the ground of the circuit. Two-phase flow was created using air injected at the bottom of the pipe filled with water. To create different flow patterns in the pipe, air flow is introduced from solenoids valves that control the air bubbles injected in the airlift pump.

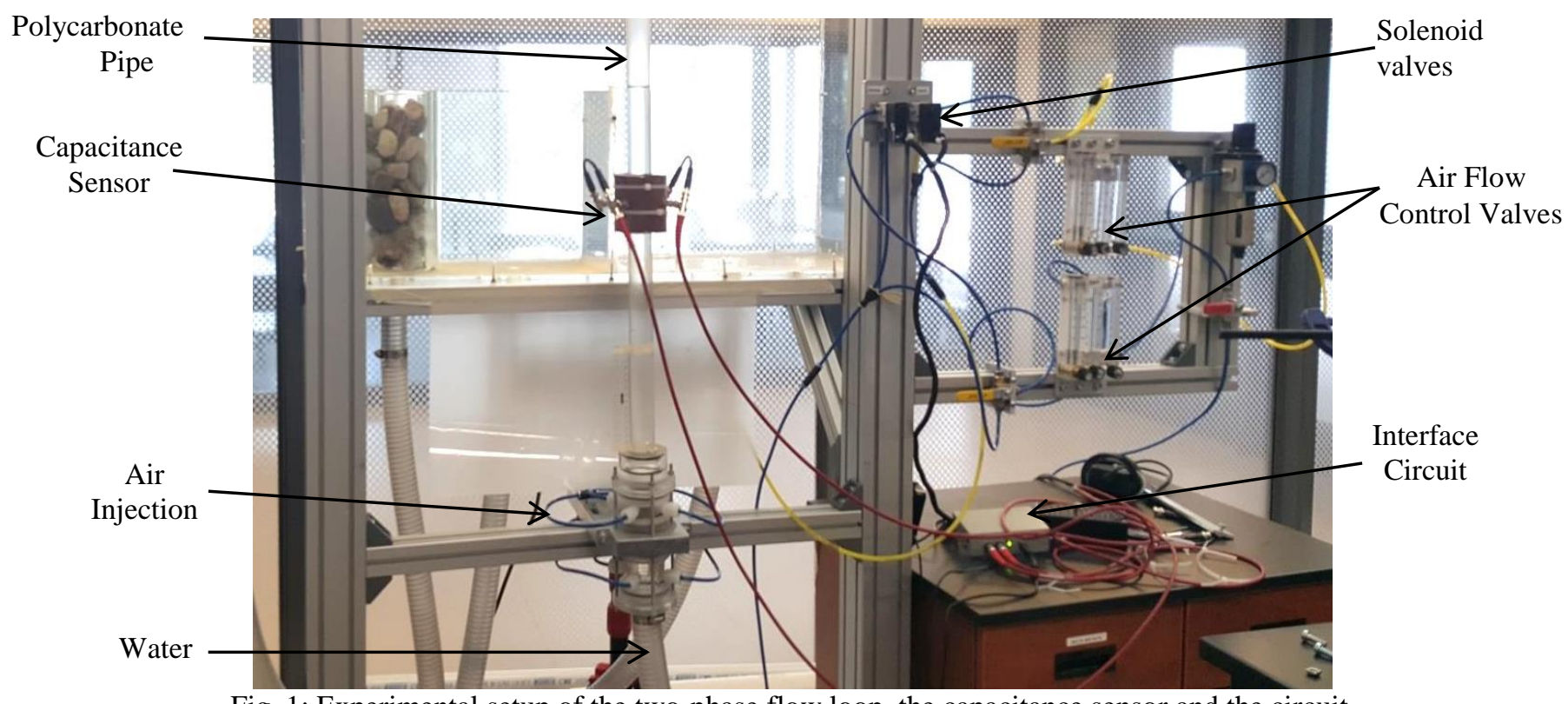

Fig. 1: Experimental setup of the two-phase flow loop, the capacitance sensor and the circuit. 


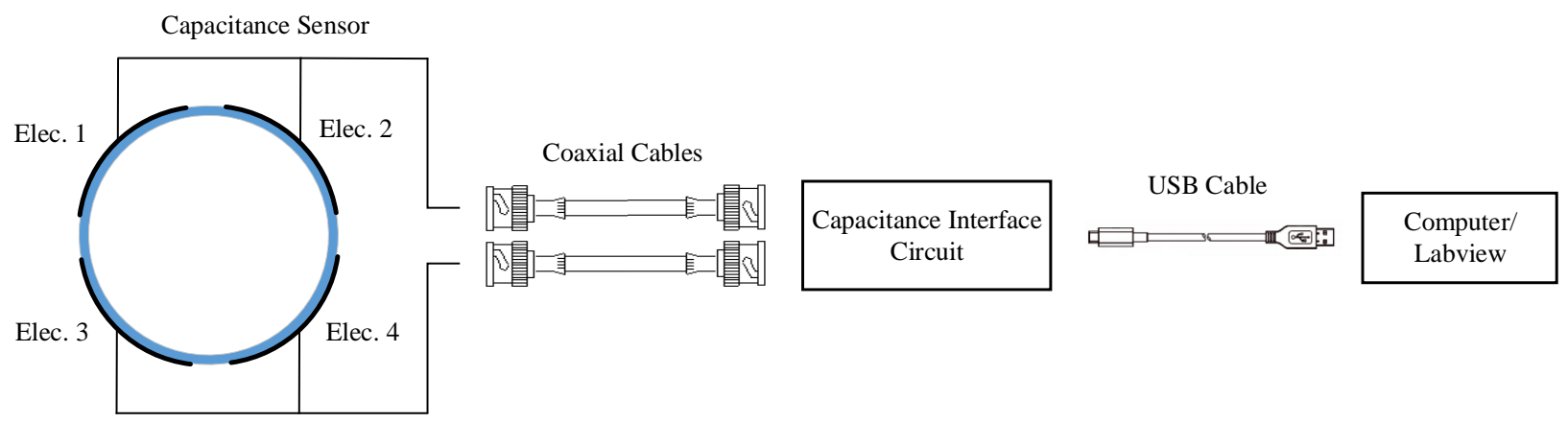

Fig. 2: Block diagram of the capacitance sensor system.

\subsection{Interface Circuit Design}

The interface circuit shown in fig. (3) consists of three main parts: a parallel LC circuit, a Frequency-to-DigitalConverter (FDC2214) and an Arduino Due micro-controller. The LC circuit is connected to the input channel of the capacitance-to-digital converter (FDC). The FDC measures the oscillation frequency of the LC circuit and converts it into a digital value that is proportional to the measured frequency. The FDC has a high resolution of 28 bits and has a maximum sampling frequency of 2500 sps for a single active channel.

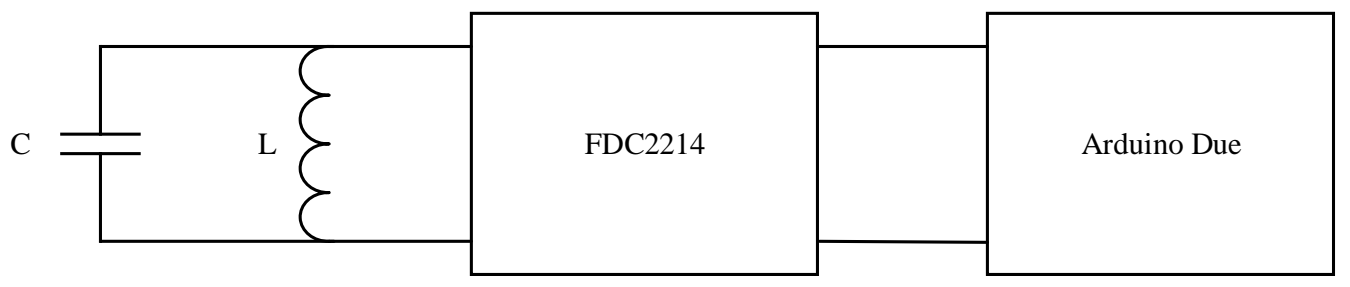

Fig. 3: Block diagram of the interface circuit.

The capacitor and inductor values used in the LC circuit are $18 \mu \mathrm{H}$ and 33pF respectively. Parasitic capacitance added by the wires, pins, coaxial cables and the sensor electrodes was found to be $60 \mathrm{pF}$, which bring the total capacitance to 93 $\mathrm{pF}$. Since the LC circuit is connected parallel to the capacitance sensor, the excitation frequency of the sensor is equal to the oscillating frequency in the LC circuit which is equal to:

$$
f_{\text {sensor }}=\frac{1}{2 \pi \sqrt{L C}}=\frac{1}{2 \pi \sqrt{18 * 10^{-6} * 93 * 10^{-12}}}=3.89 \mathrm{MHz}
$$

The excitation frequency is constantly measured by the FDC using an internal reference clock frequency $f_{\text {ref }}$ of 40 MHz .The digitized output raw_data of the FDC module is :-

$$
\text { raw_data }=\frac{f_{\text {sensor }} * 2^{28}}{f_{\text {ref }}}=\frac{f_{\text {sensor }} * 2^{28}}{40 * 10^{6}}=6.71 * f_{\text {sensor }}
$$

The FDC output is sent the Arduino where the signal is conditioned using an Infinite Impulse Response (IIR) filter and then converted from frequency back in to its equivalent capacitance value using eq. (3) and (4). Finally, the capacitance values are sent to LabView where the signal is displayed and the void fraction is calculated. 


\section{Results}

The developed system was test on a single bubble as well as three different flow patterns: bubbly flow, plug flow and churn flow. Sensor static calibration was performed using the variable water levels in horizontal pipes before running the experiments. The variance between $0 \%$ and $100 \%$ void fraction was found to be $9.3 \mathrm{pF}$.

a)

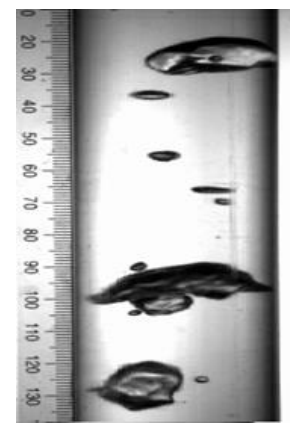

Bubbly Flow

b)

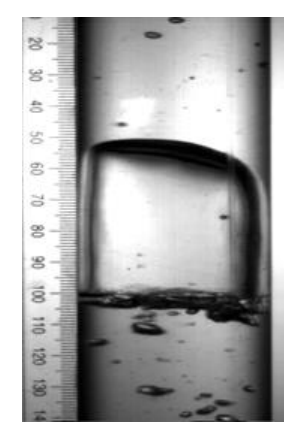

Plug Flow

c)

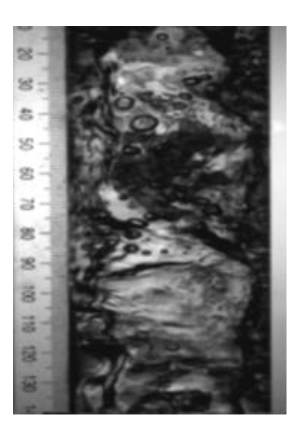

Churn Flow
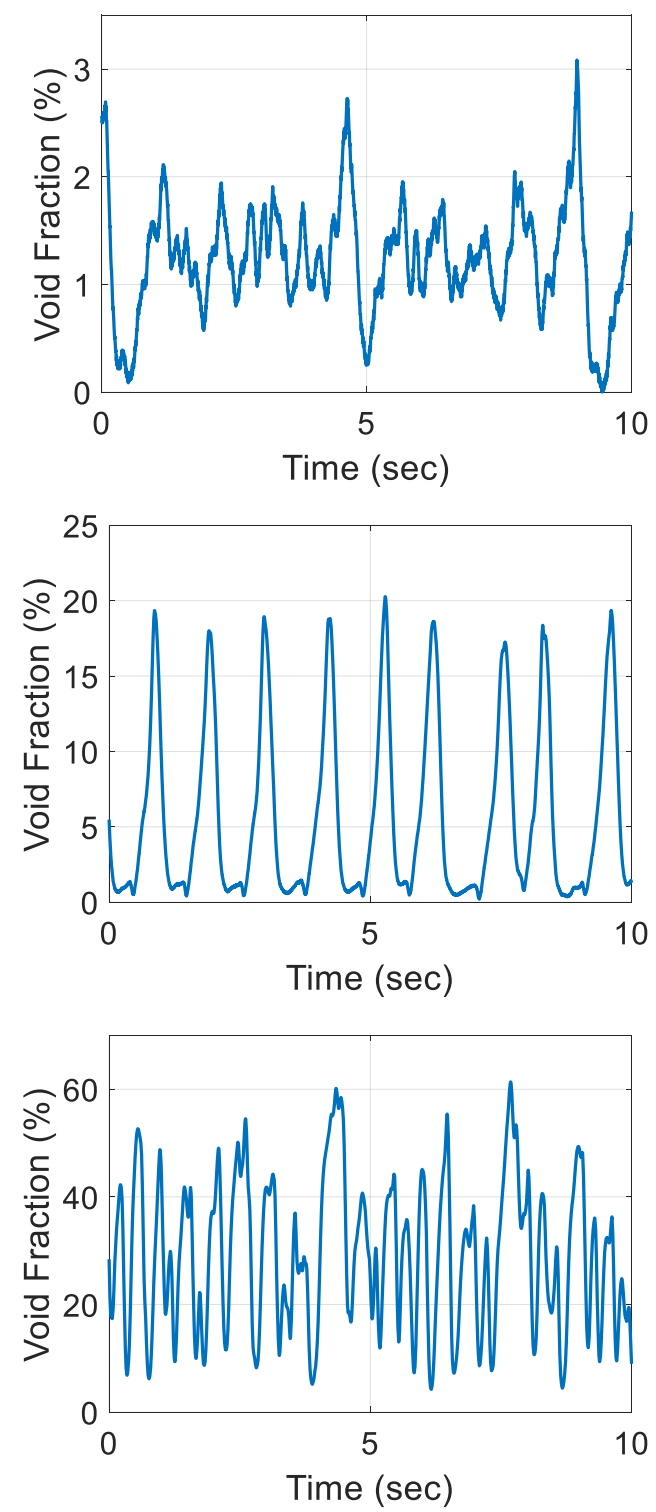
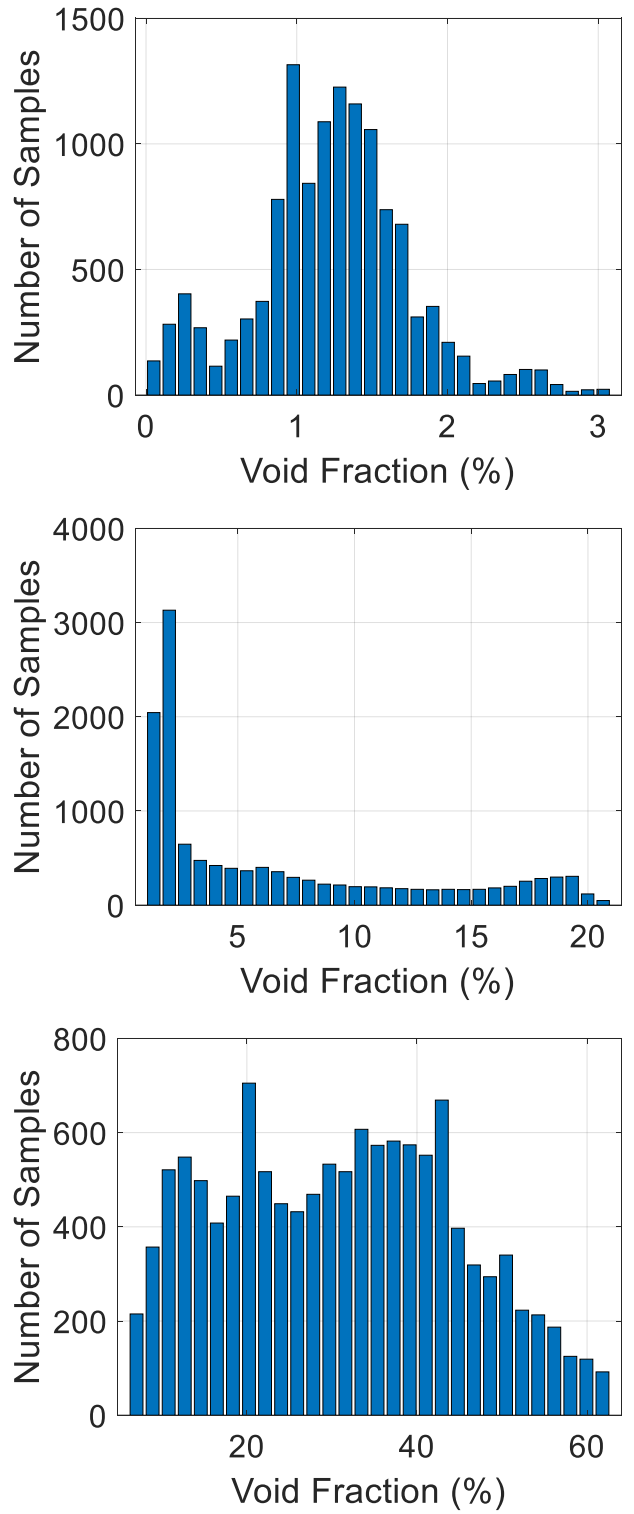

Fig. 4: Sensor output signals and probability density function for: a) bubbly flow; b) plug flow; and c) churn flow.

Fig. 4 shows the high-speed camera images of the bubbly flow, plug flow and churn flow which were used for the experiments. For each flow pattern, the real-time void fraction signals, probability density function and the time-averaged void fraction were recorded at a sampling frequency of $1250 \mathrm{sps}$ for a duration of $10 \mathrm{sec}$. Therefore, the total number of samples collected for the each of the three flow patterns is 12500. As can be seen from the results, each flow pattern shows a distinct dynamic signal hence the flow pattern can be easily identified. A summary of the time-averaged void fraction for the three flow patterns over $10 \mathrm{sec}$ is shown Table (1). It was found that churn flow had the highest time-averaged void fraction of $31 \%$ while the bubbly flow had the lowest at only $1 \%$. 
Table 1: Summary of time-averaged void fraction.

\begin{tabular}{|l|c|}
\hline \multicolumn{1}{|c|}{ Flow Pattern } & Time-Averaged Void Fraction (\%) \\
\hline Bubbly Flow & 1 \\
\hline Plug Flow & 7 \\
\hline Churn Flow & 31 \\
\hline
\end{tabular}

\section{Conclusion}

A high resolution capacitance sensor system was developed for two-phase flow void fraction measurements. Capacitance of the flow channel is measured using the LC approach therefore it is highly immune to noise interference due to the narrow band characteristics of the LC circuit. The electrode excitation frequency is high enough to overcome the errors involved when conductive fluids are used. Instantaneous change in the excitation frequency measured by the circuit represents the change in sensor capacitance resulting from the change in two-phase flow void fraction in the channel. The time-averaged void fraction calculated by LabView represents the average void fraction over a specific period of time or for a certain number samples. It was found that churn flow had the highest time-averaged void fraction while bubbly flow had the lowest. Each of the three flow patterns which were tested had a unique dynamic signal characteristics which can be used in flow pattern identification.

\section{Acknowledgement}

The authors would like to acknowledge the support of Natural Sciences and Engineering Research Council of Canada (NSERC). The technical support of FloNergia Inc. () in designing the sensors is greatly appreciated.

\section{References}

[1] T. Kuwahara, F. D. Vuyst, and H. Yamaguchi, "Flow regime classification in air-magnetic fluid two-phase flow," Journal of Physics: Condensed Matter, vol. 20, no. 20, p. 204141, 2008.

[2] J. R. Thome, (2004), Engineering data book III. Wolverine Tube Inc, 2010.

[3] V. Bertola, "Two-Phase Flow Measurement Techniques," Modelling and Experimentation in Two-Phase Flow CISM International Centre for Mechanical Sciences, pp. 281-323, 2003.

[4] L. P. M. Colombo, M. Guilizzoni, G. M. Sotgia, S. Bortolotti, and L. Pavan, "Measurement of the oil holdup for a two-phase oil-water flow through a sudden contraction in a horizontal pipe," Journal of Physics: Conference Series, vol. 501, p. 012015, 2014.

[5] O. Rodriguez and R. Oliemans, "Experimental study on oil-water flow in horizontal and slightly inclined pipes," International Journal of Multiphase Flow, vol. 32, no. 3, pp. 323-343, 2006.

[6] E. Nazemi, S. Feghhi, G. Roshani, R. G. Peyvandi, and S. Setayeshi, "Precise Void Fraction Measurement in Twophase Flows Independent of the Flow Regime Using Gamma-ray Attenuation," Nuclear Engineering and Technology, vol. 48, no. 1, pp. 64-71, 2016.

[7] M. Du, N.-D. Jin, Z.-K. Gao, Z.-Y. Wang, and L.-S. Zhai, "Flow pattern and water holdup measurements of vertical upward oil-water two-phase flow in small diameter pipes," International Journal of Multiphase Flow, vol. 41, pp. 91-105, 2012.

[8] M. S. Rocha and J. R. Simões-Moreira, "Void Fraction Measurement and Signal Analysis from Multiple-Electrode Impedance Sensors," Heat Transfer Engineering, vol. 29, no. 11, pp. 924-935, 2008.

[9] Y. Sakamoto, T. Sato, and H. Kobayashi, "Development study of a capacitance void fraction sensor using asymmetrical electrode plates," Journal of Fluid Science and Technology, vol. 11, no. 2, 2016.

[10] W. H. Ahmed, "Capacitance Sensors for Void-Fraction Measurements and Flow-Pattern Identification in Air-Oil Two-Phase Flow," IEEE Sensors Journal, vol. 6, no. 5, pp. 1153-1163, 2006.

[11] K. J. Elkow, and K. S. Rezkallah, "Void fraction measurements in gas-liquid flows using capacitance sensors," International Journal of Multiphase Flow, vol. 7, no. 8, p. 1153, 1996.

[12] E. D. Reis and D. D. S. Cunha, "Experimental study on different configurations of capacitive sensors for measuring the volumetric concentration in two-phase flows," Flow Measurement and Instrumentation, vol. 37, pp. 127-134, 2014. 
[13] S. M. Huang, A. L. Stott, R. G. Green, and M. S. Beck, "Electronic transducers for industrial measurement of low value capacitances," Journal of Physics E: Scientific Instruments, vol. 21, no. 3, pp. 242-250, 1988. 